\title{
Patched image due to pre-Descemet remains after Descemet membrane endothelial keratoplasty
}

\section{Imagen parcheada por permanencia de la capa predescemética tras queratoplastia endotelial de membrana de Descemet}

\author{
Irene Blanco-Domínguez*, Josep Torras-Sanvicens, and Jorge Peraza-Nieves
}

Instituto Clínic de Oftalmología (ICOF), Hospital Clínic, Barcelona, Spain

We report a 59-year-old pseudophakic female patient with endothelial decompensation caused by Fuchs endothelial dystrophy who underwent an uneventful DMEK with good postoperative recovery. One month after surgery, visual acuity was 20/20 and slit-lamp examination showed a clear central cornea with a patched image suggestive of pre-Descemet's layer at the interphase $e^{1,2}$ (Figure 1a). Swept-source anterior segment optical coherence tomography (SS-AS-OCT) (Topcon DRIOCT Triton Swept-source OCT ${ }^{\circledR}$ ) examination reinforced the suspicion that the pre-Descemet's layer was partially removed during descemetorrhexis, showing a double layer image (superposition of the graft over the recipient's pre-Descemet layer). (Figure 1b).

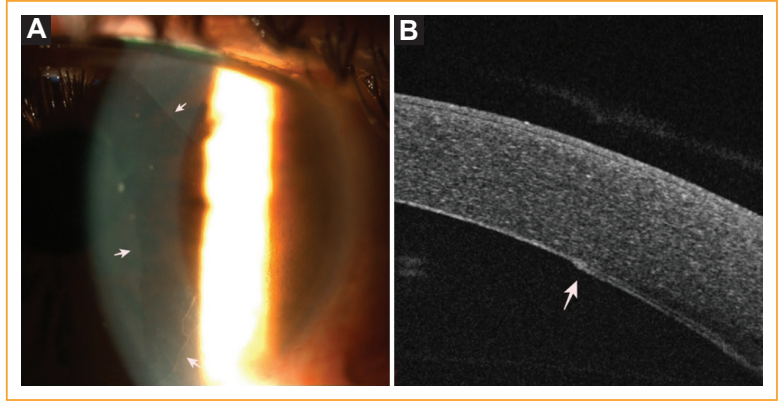

Figure 1. A: slit lamp image. White arrows show the graft area without pre-Descemet's layer or Dua's layer. B: SS-AS-OCT examination. The white arrow shows the double layer (DMEK graft + host pre-descemetic Dua's layer).

\section{Conflicts of interest}

Authors declare not to have any conflicts of interest.

\section{Ethical disclosures}

Protection of human and animal subjects. The authors declare that no experiments were performed on humans or animals for this study.

Confidentiality of data. The authors declare that they have followed the protocols of their work center on the publication of patient data.

Right to privacy and informed consent. The authors have obtained the written informed consent of the patients or subjects mentioned in the article. The corresponding author is in possession of this document.

\section{References}

1. Agarwal A, Dua HS, Narang $P$, Kumar DA, Agarwal A, Jacob $S$, et al. Pre-Descemet's endothelial keratoplasty (PDEK). Br J Ophthalmol. 2014;98:1181-5.

2. Dua HS, Faraj LA, Said DG, Gray T, Lowe J. A novel pre-Descemet's layer (Dua's layer). Ophthalmology. 2013;120:1778-85.

Available online: 13-04-2021 Rev Mex Oftalmol (Eng). (ahead of print) www.rmo.com.mx 2604-1731/@ 2020 Sociedad Mexicana de Oftalmología. Published by Permanyer. This is an open access article under the CC BY-NC-ND license (http://creativecommons.org/licenses/by-nc-nd/4.0/). 